\title{
Creativity, Labour, and the Politics of Profit in the Improvised Music Field
}

\author{
Peter David Johnston
}

\section{Introduction}

Improvisation is at once a mundane activity we engage in every day in our social interactions, and a profound one that can result in transformative aesthetic experiences. The everyday aspect of improvisation tends to be overshadowed in Western culture by the more conspicuous improvisatory practices that inform certain artistic fields, such as sketch theatre and jazz. ${ }^{1}$ These two art forms are marked as unique by their difference from the scripted dramas and notated scores that undergird the dominant conception of the performing arts in Western culture. The primacy of fixed works in the art field, in conjunction with the modernist ethos of improvising musicians since the formative work of Charlie Parker and other jazz musicians in the 1940s, means that despite its ubiquity in everyday life and non-Eurocentric musics, improvisation is discursively constructed in middle-class society as an edgy, radical, and potentially subversive activity. In this cultural context improvisation has become synonymous with creativity, making it an attractive concept for subjects and institutions looking to challenge the normative foundations that regulate the particular fields in which they work.

Improvisation researcher Ajay Heble hypothesizes that "musical improvisation is a crucial model for political, cultural, and ethical dialogue and action," and that "communities based on such forms are politically and materially pertinent to envisioning and sounding alternative ways of knowing and being in the world" (par. 2). Although there is no agreement on an ontology of musical improvisation in either the popular or scholarly domains, recent writings in music studies and the humanities have proposed that the improvisatory practices of jazz and related musics can be productively applied to contexts outside of the arts to address static, unethical, or otherwise outmoded ways of organizing society. ${ }^{2}$ In this context I will examine the emerging trend in business studies in which management theorists look to group musical improvisation as a model for corporate design.

Proponents of arts-based management strategies argue that applying the frame of improvisation to the organizational schema of the workplace can help companies better respond to the shifting demands of the market. R. Keith Sawyer writes:

In today's economy, innovations emerge from improvisational teams ... In both a jazz group and a successful work team, the members play off of one another, with each person's contributions inspiring the others to raise the bar and think of new ideas. Together, the improvisational team creates a novel emergent product, one that is more responsive to the changing environment and better than what any one team member could have developed alone ("Education for Innovation" 43).

Writing in more general terms, but articulating similar ideas, management theorist Nancy Adler states: "Given the dramatic changes taking place in society, the economy, and technology ... [designing] innovative options requires more than the traditional analytical and decision-making skills taught during the past half century in most MBA programs. Rather, it requires skills that creative artists have used for many years" (489). Management theorists' discovery of improvisation as a frame for reforming business practices is part of a much longer trend of business leaders looking to the cultural field for new ideas-Fredric Jameson notes that commodity production in capitalist societies, including "our clothing, furniture, buildings and other artefacts, [is] intimately tied in with styling changes which derive from artistic experimentation" (The Cultural Turn 19). It is clear that management theorists, as part of the research and development wing of capitalism, see an opportunity to advance the priorities of business through adapting artists' practices to develop "novel emergent products"; it is less clear how this discovery will benefit artists as subjects living on the economic margins of capitalist society.

If improvisatory practices promote, in Heble's words, "dynamic exchange of cultural forms" and "new, socially responsive forms of community building" (par.2), what happens when they are used to create commodities for sale on the market? The community-building in this instance will be based on the familiar patterns of production, consumption, and wealth accumulation that are eroding the social wage and increasing income disparity around the world. This analysis of the efforts of management theorists to deploy improvisation in for-profit enterprises will reveal the contradictions between capitalism's imperatives and the democratic, egalitarian aims of those who identify as improvisers. If the artistic practices of improvisers are removed from their marginalized social context and placed at the centre of the dominant economic system, we must account for how these practices will be used, by whom, and to what end. 
To address the implications of using group musical improvisation as a model for restructuring business I will draw on ethnographic research conducted in the improvised music fields in London, England, and Toronto, Canada, putting the ideas and experiences of subjects who identify as improvisers in dialogue with those of researchers who are looking to the arts for "new ... and more innovative ways of managing" (Adler 486). My analysis will start with a description of how improvisers narrate their activities, and how this narrative has been taken up in recent scholarship on improvisation; from there I will explore the role of management theorists within the capitalist system. I will conclude with a case study comparing the organizational structure of an improvising ensemble with that of a capitalist enterprise, and offer some speculations about the role improvisation might play in calling attention to the inherent problems of the currently dominant economic system.

\section{Imagining the Improviser}

The ideological foundation of much recent scholarship involves interpreting improvisation as a counter-hegemonic activity, a practice that can bring about change to an undesirable situation. This discursive manoeuvre is supported by improvisers' commentary on their own work, as many have openly declared their interest in using the concept to address a range of social issues relating to race, class, gender, and various notions of freedom. A short list of artists whose musical practices and political spirits inform recent interdisciplinary scholarship on improvisation includes: The Association for the Advancement of Creative Musicians (AACM) and the Black Artists Group (BAG), African American artist collectives dedicated to advancing opportunities for black musicians in a white-dominated cultural field; the Feminist Improvising Group (FIG), a London-based group of women improvisers that challenged the male-dominated improvised music scene in England; AMM, a London-based improvising ensemble that includes percussionist Eddie Prévost, who has written extensively on democratic modes of music making; and Le Quatuor de Jazz Libre du Québec, who used free jazz as a way to participate in the sovereignty debates during the Québécois Quiet Revolution in the late 1960s. Eddie Prévost summarizes the ethos represented in these examples with the assertion that historically, musicians who have made "improvisation the aesthetic priority of their creative lives" have done so as a response to a "political and social system not of their making or liking" (37).

The explicit political aims of these improvising groups are mirrored in the modernist aesthetic priorities of many who claim the identity of improviser. Improvisers' prioritization of musical experimentation, in conjunction with a general aversion to the materials of popular music, makes their music challenging for many listeners, and by extension difficult to commodify and sell. In response to their persistent economic marginalization, improvisers and interested audience members have developed a network of alternative structures to support their creative practices. This network operates with very little financial capital; according to improviser and record store owner Mark Wastell, the improvised music field exists because of individuals who are willing to "run concerts, festivals and labels to little reward outside of the immediate scene." English guitarist Derek Bailey's description of improvised music performances in London reveals the politics and pragmatism of the field:

The bulk of freely improvised music, certainly its essential part, happens in either unpublicised or, at best, under-publicised circumstances: musician-organised concerts, ad hoc meetings and private performances. In other words, simply in response to music making imperatives. And it's easy to see that the more conducive the setting is to freely improvised music, the less compatible it is likely to be with the kind of presentation typical of the music business (141).

Bailey's notion that improvisers are motivated by "music making imperatives" rather than money offers a useful frame for understanding their willingness to continue producing musical culture despite the lack of financial support for doing so.

American bassist Barre Phillips' description of his life as a musician demonstrates that the decision to pursue improvisation as a music-making imperative has meaningful material consequences for practitioners:

Sometime around 1975 I made the choice to play improvised music, which I did for social reasons, to take a stance. In the overall scene I think it's important that there is the improvised music experience, next to the commercial use of music. This choice meant finding a way to afford to do it, so we developed a very lowbudget living situation, where we lived for ten years without a telephone or electricity.

These accounts from established improvisers reveal that the improvised music field persists through the commitment of artists and audiences to the particular political and aesthetic ideals they attach to the idea of improvisation. Although it is too much to claim that all improvisers hold communitarian, anti-capitalist political ideals, most committed improvisers are willing to lead materially modest lives, either subsisting or seeking the necessary income elsewhere rather than changing their music to suit the demands of the music business. 
Given the political history and cultural context of improvised music, the art trend in management theory raises important issues around cultural appropriation and the co-option of counter-hegemonic practices for commercial ends. Eddie Prévost describes the patterns that have emerged from interactions between the business and cultural fields: "Artists who have a political agenda are generally working around the edges of the societies in which they live, sniping, trying to outrage and morally undermine the general cultural hegemony ... in the longer term we can note that the best of these creative outbursts are usually absorbed into the very system they allegedly opposed" (55). Even as capitalism is dependent on the arts for new ideas, artists as citizens are subjected to perpetual financial hardship, as the wealth derived from their artistic experimentation does little to stem the rising costs of living in advanced capitalist societies. The lived experience of improvisers thus makes them distrustful of profit-focused initiatives that arise from the general cultural hegemony.

The historic connections between improvisation and the African American struggle for civil rights, improvisers' resistance to the commercialization of their music, and the persistence of an alternative network of artistic production have resulted in improvisation being positioned in recent humanities scholarship as a kind of embodiment and practice of critical theory. It is important to note that in the following analysis I do not contend that improvisation is an inherently counter-hegemonic activity, for it can be employed in the creation of commercial music as easily as art music, and indeed in situations where much more is at stake than in the typical exchanges of the cultural field. However, improvisers' activities, like those of experimental artists working in other art forms, have resulted in the establishment of alternative networks of cultural production and social relationships based on different priorities than those that motivate capitalists. In the present context, the ideological foundations of oppositional cultural fields are the primary issue, rather than the details of a particular art practice. Although I will be attending specifically to improvised music in this analysis, the problems around co-option and inequality that emerge through my description of the art trend in management theory are relevant for other forms of oppositional culture that might attract the attention of those working to refine the capitalist system.

\section{Business Unusual: Improvisation under Capitalism}

Despite their investment in resisting cultural hegemony through the production of occasionally challenging, often dissonant, and decidedly non-profitable music, improvisers must live inside the capitalist system, so it is necessary to provide context for this specific investigation by conducting a general analysis of the ideologies and structures that regulate the actions of both capitalist and anti-capitalist groups. According to Luc Boltanski and Eve Chiapello, capitalism is regulated by three main imperatives: unlimited accumulation by peaceful means; competition as the best means to stimulate creative thinking; and a division of labour between those who own the means of production and those who must make money through the sale of their labour (162). Capitalists argue that adhering to these imperatives will lead to collective prosperity (via the trickling down of financial capital through the social strata), social equality (understood as the possibility of upward social mobility through hard work and equality of opportunity), increased individual liberties, and a safe and secure society. Yet analyses of long-term economic cycles-such as Giovanni Arrighi's The Long Twentieth Century and the work of American theorist Fredric Jameson-suggest that capitalism's core operational principles work against the fulfilment of these promises, resulting in an inexorable march towards unjust wealth distribution and overwhelming social inequality. These and other critics argue that capitalism is a dialectical system: it promises prosperity for all, fulfils this promise for a few, but ultimately works against the interests of the majority by concentrating wealth at the top of the social hierarchy.

In spite of escalating social inequalities in the advanced capitalist societies of North America and Western Europeas illustrated by the ongoing fallout from the 2008 mortgage crisis in the United States, the sovereign debt problems in the European Union, and the Occupy Movement-capitalism's promises of future prosperity have proven attractive enough to allow it to maintain its hegemonic status. Boltanski and Chiapello write: "The capitalist system has turned out to be infinitely more robust than its detractors, starting with Marx, had ever imagined" (163). They go on to expand on Antonio Gramsci's conception of hegemony by hypothesizing that critiques of capitalism often support, rather than disrupt, subjects' acceptance of its imperatives:

we affirm that criticism is a catalyst for changes in the spirit of capitalism. It is impossible for capitalism to avoid being at least somewhat oriented towards the attainment of the common good, as it is this striving which motivates people to become committed to its process ... So capitalism needs its enemies, people who have a strong dislike for it and who want to wage war against it. These are the people who provide it with the moral foundations that it lacks, and who enable it to incorporate justice-enhancing mechanisms whose relevancy it would not otherwise have to acknowledge (163).

Boltanski and Chiapello make the important point that capitalism's need for our continued commitment to its process means that its promises are not simply illusions we are duped into believing; by making some real concessions to the common good, it demonstrates that it is a responsive system that continually self-adjusts towards the goal of a more 
prosperous future. If a critical mass of the public accepts these regular adjustments as ultimately beneficial for them, the institutions that determine the distribution of goods can continue to operate on their existing terms. Critics thus occupy an important role in ensuring capitalism's longevity and legitimacy, participating in a negative feedback loop in which governments and capitalist enterprises continually adjust their practices to maintain a balance between the discrete imperatives of accumulation and public commitment.

Management theorists function as the internal critics of capitalism, researchers whose job is to analyze existing models of business organization and propose new ways to enhance market competitiveness. R. Keith Sawyer's description of how the collaborations that are typical in improvised music can be made operational in a business context is illustrative of the basic discursive framework of management theory:

[In] many businesses, work teams [could be] tasked not only with efficient execution, but also with creative problem solving or even with developing ideas for new products. Such groups could be videotaped and the interactions could be analyzed to help us better understand how collaboration generates business innovation ("Distributed Creativity" 91).

Quoting organizational speaker and poet David Whyte in her article "The Arts and Leadership," Nancy Adler similarly positions the things managers can learn from artists in terms of competition and commodity production:

[The artist] must rely on the embracing abilities of their imagination to intuit and describe what is as yet a germinating seed in their present time ... the present manager must learn the same artistic discipline, they must learn to respond or conceive of something that will move in the same direction in which the world is moving ... To wait for all the evidence is to finally recognize it through a competitor's product (Whyte 241-2).

These comments reveal that even as they propose alternative and novel business models, management theorists' critiques are firmly embedded in the discourse of capitalism. They acknowledge that the system requires regular, incremental changes to its surface-level operational procedures, but implicitly accept the imperatives of accumulation, competition, and labour hierarchy as the foundations of prosperity.

The arts-based organizational strategies advocated by management theorists promise benefits for workers at the individual, subjective level, including: increased workplace freedom through the restructuring of hierarchies, the opportunity to think and act creatively rather than being restricted to following orders, more variety on the job as workers move from project to project, and the possibility of increased emotional investment in one's work. Business theorist Yochai Benkler writes, "success in business-any business—isn't achieved through rigid corporate hierarchies or astronomical CEO pay packages, but by fostering an inclusive, social, and collaborative workplace where performance is intrinsically rewarding" (211). The implicit argument in management discourse is that these changes in the organization of work will result in benefits at the intersubjective level, as prosperity will flow outwards from the corporate sector to enrich society in general. Although we can take management theorists at their word that the practices of musical improvisers can aid businesses in enhancing their productivity and efficiency, based on recent events and historical patterns there is little evidence to support the belief that "business innovation" will benefit anyone other than the owners and managers who are being urged to embrace the "artistic discipline." It is also worth noting that even as their practices are at the core of these developments in management theory, artists themselves, as subordinate subjects whose discipline and imaginations are to be modeled by the dominant group, are rendered invisible in the literature. Management theorists clearly accept capitalism's promises of eventual prosperity through business innovation, so they see no need to account for how their actions might contribute to the perpetual marginalization of those whose practices they have co-opted.

In contrast to the surface adjustments proposed by management theorists as refinements of the system, improvisers' critiques are based on the assumption that substantive structural changes are required to address the long-term deleterious effects of capitalism. Boltanski and Chiapello note that the practices and commentaries that emerge from "small artistic and intellectual circles" tend to criticize "oppression (market domination, factory discipline), the massification of society, standardisation, and pervasive commodification" (176). In my ethnographic research, improvisers tended to balance specific concerns around the culture industry with more general critiques of the "inequalities, misery, exploitation, and the selfishness of a world that stimulates individualism rather than solidarity" (Boltanski and Chiapello 175). Non-profit, artist-run initiatives such as the AACM, Eddie Prévost's weekly improvisation workshop in London, Somewhere There in Toronto (a musicians' collective dedicated to providing a performance venue for improvisers), and the Vision Festival in New York, among many other examples of groups and events orientated around the notion that art production is a "powerful political act" (Vision festival website) reflect the desires of improvisers to address these issues. The economic realities of modern capitalism mean that even those improvisers who act without an explicit social justice agenda must actively engage in the search for alternatives to the dominant circuits of cultural production, for their aesthetic ideals put them at odds with profit-focused venues, 
festivals, and media. In acting together to claim a cultural space that prioritizes sustainability over profit, improvisers nurture opportunities to develop social relationships based on solidarity rather than individualism.

Improvisers represent a small component of the wider social justice movement; within that movement their focus on art practice situates them in a particular rarified position in relation, for example, to labour and environmental activists. Yet at the present moment, their practices have attracted the attention of those at the centre of hegemonic culture, as the use of jazz ensembles as a metaphor for creative, collaborative work is becoming increasingly common. Is it possible that the art trend in management theory offers the opportunity for improvisers to push for meaningful social change through their newfound access to the business field? Any chance for gain in this scenario is contingent on business leaders recognizing that the originality, vitality, and resiliency of artists' work emerges from a different set of priorities than those determined by the imperative of accumulation. Perhaps through exposure to this counterhegemonic ethos, those at the centre of dominant culture will begin to question their current priorities. But we have been here before-throughout the twentieth century capitalism proved to be adept at absorbing critiques from the few on the margins and making surface-level changes to ensure the continued participation of the many in the middle. As Boltansky and Chiapelo write of the 1968 crisis in France:

The incorporation of many components of artistic criticism into the new spirit of capitalism deprived earlier critics of reasons for feeling discontented-and rendered them insensitive to the superficiality of the achievements of the so-called liberation movement. Moreover ... [in France] many supporters of artistic criticism have been co-opted into the power elite (178).

Given this historical context, it seems unlikely that contemporary management theorists- who, as subjects invested in capitalism's promises, profit from their contributions to the system-will be inclined to address the concerns of those whose practices they have co-opted. Nevertheless, it remains important to assert some sort of agency in this process, in the hope that a critical reading of their work will reveal to management theorists and business leaders that there are other ways of organizing society.

\section{Sounding The System}

In the following section I will draw on my personal experience as an improviser and bandleader to analyze the working methods of contemporary improvising ensembles. This practice-based account is intended to add material detail to the theoretical analysis above. Using the critical framework contained in Heble's assertion that "musical improvisation is a crucial model for political, cultural, and ethical dialogue and action" (par. 2), I will situate the practices of improvising ensembles in relation to the capitalist imperatives of competition, labour hierarchy, and accumulation. In the process of making these specific comparisons, a description of the general organizational structure of the improvised music field will emerge that provides further context for understanding the relationship between improvising artists and management theorists.

In capitalist discourse, competition is integral to innovation-economists perpetually evoke competition for profit as a necessary motivator for creative thinking. Improvising ensembles also prioritize innovation-as Scott Thomson (2007) notes, the vitality of improvised music depends on an ongoing critical reevaluation of one's musical materials, and on the constant search for new sounds and musical relationships. Despite this shared priority there is an important distinction in the two spheres. Innovation in business is inherently teleological, as the goal is to produce a new, better product before one's competition does. Once the shelf life of a particular product is reached, a new or updated version must be created to keep the company in business. This constant cycle of obsolescence means that some businesses survive while others fold, that finite natural resources are consumed as outdated products are replaced, and that businesses are compelled to act out of self-interest to stay profitable.

Innovation in improvised music is substantially different, as the intentional avoidance of the materials of commercial music means that there is little profit incentive for creative thinking, and few resources are expended through musical performance. More importantly, improvisers prioritize the process of creation rather than the products that may emerge from an improvised musical exchange. Steve Noble, who has worked as an improviser in London since the early 1980s, described the economic context for improvised music:

I'm not in this to make money. I'd like to, but the reality is that it doesn't seem to work unless you can find an income from copyright, which is the backbone of capitalism. You get something that pays you an awful lot because it's played over and over again. But the very nature of improvising is that you do it live. It's very hard then to claim a kind of copyright, or royalties from the PRS [Performing Right Society in England].

Noble reaffirms the low financial stakes in the improvised music field, and alludes to how improvisers' focus on live performances results in musical practices that are constantly shifting, making their innovations difficult to copyright 
and claim as property. Participants in the improvised music field valorize innovation and experimentation, and the idea that each performance will be different and non-repeatable. Improvising musicians who develop specific, individual sounds_-such as saxophonist Evan Parker's highly developed circular breathing technique, and Eddie Prévost's use of string instrument bows and automated toys on cymbals-view their practices as part of an ongoing creative project rather than an end-focused process of research and development. Audiences go to hear improvisers do the things they have become known for, but they listen for how these musicians develop variations of their basic materials and adapt their sounds to different performing situations.

Although certain improvisers have become associated with specific practices (and it should be noted that Parker and Prévost do not claim to have invented the particular techniques they are known for), other improvisers are free to take up these techniques towards the "creation of [their] own musical material and lexicon" (Lewis 83). Once performed publicly or documented on recordings, new sounds become accessible to all improvisers, and may become part of the basic vocabulary of the improvised music field. Despite how improvisers are forced to constantly compete with each other for meager performance opportunities and financial resources, the improvised music field remains a fundamentally collaborative space, where participants are expected to use existing techniques and musical materials to develop their own creative practices. The improvised music field thus offers a counter-example of how vital and creative ideas can grow without the profit motivation and property regulations that capitalists insist are necessary for fostering innovative thinking.

Labour hierarchies in the improvised music field are also significantly different than in the business field. Profitfocused businesses are determined by the division of labour between owners and employees, and by the different pay scales related to the various positions within an organization. On the surface, an improvising ensemble features a similar division of labour-there is usually a leader who organizes the performances and recordings, who may write the music and the grant applications, and whose work off the stage generally ensures the continued existence of an ensemble or project. This leader may take ownership of the ensemble off stage, yet in a performance the relationships between participants have the potential to be much more fluid than in a business setting. In a collective improvisation each musician is free to shift between musical roles over the course of a performance, including (but not limited to): leading the ensemble, supporting the other voices, supplying a background texture, or, crucially, not playing at all. Scott Thomson (2007) has written concisely about the shifts in authority and leadership that characterize a successful improvised piece, so there is no need to repeat these details here beyond reiterating his assertion that the labour and responsibility for the quality of an improvised musical performance is shared equally by all those involved.

This organizational model has obvious parallels to the improvisational "work teams" Sawyer proposes, but it is a crucial distinction that an improvising ensemble is not regulated by an external overseer, as Sawyer suggests is necessary for the effective harnessing of creative energy in a business environment ("Distributed Creativity" 91). The authoritarianism of current business models is made even more clear by Google Chairman and CEO Dr. Eric Schmidt, who asserts, "You need to let the artists [in your company] explore and create the next great thing, which they will do reliably if you permit it" (Austin and Devin xvii). In a musical improvisation there is no division between the labour and managerial classes, between those doing the creative work and those who permit and then analyze the work for how it might generate business innovation. A radical rethinking of corporate design would be required in order for a business to model itself substantively after an improvising ensemble-a rethinking that promoted greater equality between workers and managers, allowed for workers to move through the hierarchy of an organization in the execution of their work, and ultimately reified this equality through a redistribution of the profits generated by collaborative work teams.

The imperative of accumulation and the related politics of wealth distribution are the most significant issues to address in analysing the ethical implications of the art trend in management theory. There are a few examples of alternative models of business organization in Western society, such as housing co-ops and credit unions, but the effectiveness of these operations are ultimately limited by the profit-focused structures that regulate capitalist society in general. Most businesses are structured to pay those in the lower levels with a fixed salary or hourly wage, while the owners, managers, and shareholders are entitled to a much greater percentage of the profit. This discrepancy is presumably to provide compensation for the financial risk the dominant group assumes in running a business, and as a reward for the creative ideas that brought the business into being in the first place, or that keep it competitive.

In previous stages of capitalism, business owners invested much of their profit back into the business to pay for research, development, and expansion, but currently an increasing percentage of this profit is being hoarded by owners, paid out to shareholders located all over the world, or simply spent on luxury items (Stanford 320-3). Fredric Jameson, following the work of Giovanni Arrighi, identifies this trend as representing a third stage of capitalism he calls "multinational capitalism"; this term marks the shift in Western societies from a production-based economy to one focused on generating profit from existing money: 
Speculation, the withdrawal of profits from the home industries, the increasingly feverish search, not so much for new markets (these are also saturated) as for the new kinds of profits available in financial transactions themselves and as such-these are the ways in which capitalism now reacts to and compensates for the closing of its productive moment (The Cultural Turn 141-2).

The frame of a post-production economy is obviously only applicable to North America and Western Europe, as there is still plenty of factory production taking place in Asia, where labour costs are much less. "Multinational capitalism" thus refers to how the growing wealth of Western societies is contingent on the cheap labour and materials available in less democratic societies. The recent increase in speculation means that a significant amount of the world's financial capital is being removed from the communities where businesses are located and where workers live and spend their wages, in favour of circulating it in the netherworld of the financial industry in the pursuit of interest returns, or simply stockpiling it out of fear of another financial crisis.

In the improvised music field, many musicians take on leadership roles that mirror the positions of managers and owners in the business field. However, in my experience these musicians, despite the extra work they put into a project, tend to distribute their profits evenly amongst all the participants, sometimes even losing money to ensure that their fellow musicians make a decent wage. In addition, many performances in the improvised music field are "door gigs," where there is no guaranteed money for musicians. Improvisers willingly participate in these events in response to their own music-making imperatives, usually splitting the donated cover charge at the end of a performance. Much of the profit that improvisers make from their music is reinvested in their immediate community through producing new recordings, renting performance and rehearsal venues, studying with a mentor, or going out to hear new music. As Barre Phillips suggests, for most improvisers the pursuit of profit is replaced by the search for sustainability-improvisers organize their lives to ensure the "improvised music experience" persists as an alternative to the "commercial use of music." Therefore, most improvisers live on the financial edge, doing whatever work they need to do to cover the cost of living, while preserving enough time to focus on their creative practices.

These specific examples of the different value systems at play in an improvising ensemble and a capitalist enterprise are illustrative of the broader dialectic of capitalism. The promises of increased collaboration and creative freedom through the application of arts-based practices in the workplace are compelling, and it is possible that once established these frameworks will improve the "efficiency and effectiveness of competition-driven production" (Boltanski and Chiapello 163). Capitalists promise that this injection of new ideas into the system will result in widespread prosperity, but this prosperity seems further away the deeper we move into the wilderness of multinational capitalism. It is becoming increasingly difficult to pursue artistic work in Western society, despite the successful use of arts-based practices documented by Sawyer, Adler, and Benkler by companies such as Apple, Toyota, and Google. These are clearly capitalist success stories, yet each carries significant baggage around, respectively, questionable labour practices in Asia, environmental impact, and the manipulation of personal information for profit. Without a substantive structural adjustment, the determining imperatives of capitalism will continue to generate social and economic inequalities over the long term, perpetuating the marginalization of artists and increasing income disparity.

\section{Towards an Ethics of Business in the Age of Improvisation}

With these issues in mind, I return to the general question of what an ethical and substantive cross-fertilization of ideas between improvising artists and management theorists might look like. As subjects who have worked for many years to build and sustain an alternative cultural field, improvisers share a profound awareness of the systemic problems that inhibit personal, collective, and creative freedoms. After many decades as a counter-hegemonic practice, we are at a moment where improvisation is now overtly in the hands of those its practitioners have long worked to oppose, so it is crucial to look for any possible disruption of the general cultural hegemony that can be made through this most recent deployment of art practices by capitalist theorists.

Improvisers' desire for artistic sustainability aligns with economist Jim Stanford's model for economic reform, which is based on another pillar of capitalism that has noticeably declined over the past few decades: investment. Stanford argues that if corporations, governments, and wealthy individuals invest a larger proportion of their profits into structures that generate income for working subjects, then more wealth would circulate to more of the world's people (320-3). In this scenario, businesses would spend more on research and development of ethical and environmentally sustainable products, and workers would have more money to spend, which by extension would generate increased tax revenue that could be transformed into essential social services. Since the mortgage crisis of 2008 and the related financial downturn across other industries, economists from both the left and right have attributed the slow economic recovery to a decline in corporate investment in the structures of production. Until this trend is reversed much of the world's wealth will remain tied up in the banks or financial markets, where it serves the needs of the already-wealthy and doesn't trickle down to the rest. 
As illustrated in the previous section, improvisers and other artists are implicitly aware of the importance of investment and equitable wealth distribution, as they tend to share their profits equally, and reinvest what they can in making new art. In this way much of the income improvising musicians get from their art practice-from either performances, government grants, or sales of recordings-gets circulated through the local community, rather than exported via the global financial markets. It is significant also that musicians share not only financial capital, but the symbolic capital of information and professional resources, such as contacts for performance venues and media outlets that support improvised music, ideas for developing new projects, and advice on pursuing public arts funding opportunities. This cycle of continual reinvestment based on the desire for collective artistic sustainability presents a counter-narrative to the competitive, profit-focused, self-interested business model that has thrived under multinational capitalism.

Stanford's argument for increased social investment is just one aspect of the potential structural realignment modelled by the improvised music field. Perhaps more crucial is the wider epistemological shift that the incorporation of improvisatory practices might generate within the business sphere. The improvised music field demonstrates how the generation of creative ideas is not dependent on competition, labour hierarchies, or the promise of individual profit, but owners, managers, and workers would need to make significant changes to their dispositions and practices in order to shift themselves away from the imperative of accumulation. They will need to acknowledge that capitalism's promises of collective prosperity are continually broken, and to alter their understandings of their social and professional roles from that of individuals participating in the process of unlimited accumulation, to a collective that is focused on contributing to the common good.

Fredric Jameson, in a discussion of the possibilities of postmodern art, summarized the substantial epistemological and behavioural changes that need to be instigated if the destructive cycles of capitalism are to be disrupted:

[The] new political art ... [will have to achieve] a breakthrough to some as yet unimaginable new mode of representing [multinational capitalism], in which we may again begin to grasp our positioning as individual and collective subjects and regain a capacity to act and struggle which is at present neutralized by our spatial as well as our social confusion ("Postmodernism" 93).

In the present analysis I have taken a different standpoint than Jameson, addressing the corporate structures that are the foundation of capitalism, rather than questioning the political potential of art. I have allowed improvisation to stand on its own as an example of counter-hegemonic discourse and practice, and will leave a more detailed, materialist analysis of contemporary improvised music as "political art" for a future project. For the purposes of this essay, Jameson's comments are relevant in that they call attention to the changes required for business leaders to undertake an ethical engagement with art practices. Benkler alludes to these issues, stressing that arts-based reforms of management structures need to be substantive rather than superficial: "[F]raming a practice or system as collaborative, or as a 'community' may encourage cooperation for a while, [but] if that claim isn't authentic and believable the cooperation won't last" (212). For the art trend in management theory to be anything other than the usual business of co-option, subjects at both the margins and the centre of hegemonic culture will need to discover and enact a new kind of agency that allows for at least an awareness, and ideally an interrogation, of the dominating imperatives of multinational capitalism.

This potential disruption can only be initiated if we envision a way out of our current "social confusion"; improvising ensembles as creative, collaborative, co-operative entities offer one possible model for reforming our dominant social system, but their relevance needs to be critiqued as well. Jameson warns that, "We cannot return to aesthetic practices elaborated on the basis of historical situations and dilemmas which are no longer ours" ("Postmodernism" 90). Improvisation has been a part of Western musical culture for over a century; its most significant political impact, in terms of cultural visibility, occurred in the 1960s during the initial free jazz revolution in the United States. This is not to say that improvisation's disruptive potential has been permanently dulled by the passage of time, but that we do need to seriously consider Jameson's assertion that the revolutionary art forms of the past do not necessarily give us the tools to deal with present social issues. I have run the risk here of fetishizing improvisation, and possibly asking more of it than is reasonable. Improvisation's power as political art is not inherent, but dependent on how those who claim it as their primary operational procedure use it to assert their individual and collective agency against the constantly shifting constraints of multinational capitalism. It is therefore crucial that we subject our art practices to the same kind of critical scrutiny that I have applied here to the art trend in management studies, for capitalism is remarkably adept at turning our creative outbursts into commodities that are sold back to us as symbols of the prosperity we are perpetually denied. 


\section{Conclusion}

Management theorists surely recognize that the dominant economic system is reaching the breaking point-our consumption of natural resources is not sustainable, and the systemic inequality of wealth distribution under multinational capitalism is resulting in civic unrest not just in chronically impoverished and disadvantaged nations, but across the wealthy countries of North America and Europe. Our situation is rendered even more untenable whenever it is revealed how much profit CEOs, corporations, banks, and money managers take home each year. Some cracks in the system are appearing, such as Greg Smith's (2012) public resignation from Goldman Sachs over unethical practices on Wall Street, but despite the ongoing economic downturn across the world, governments and corporations are doing little to address the systemic problems that allow such practices to continue. Under these conditions, a meaningful engagement with improvisation-as it is practiced by citizens who in varying ways reject the ideological framework upon which capitalism is based-will require nothing less than theorizing how to restructure the system to allow for the kinds of cooperation, innovation, profit sharing, and non-hierarchical labour structures that characterize the improvised music field. If management theorists are prepared to look beyond the surface activities of improvising ensembles, beyond the notion of harvesting creative practices to transplant into more profitable soil, they will see a model of social interaction that points towards the possibility of a more democratic, egalitarian society than the one currently supported by the business leaders they are addressing.

\section{Notes}

${ }^{1}$ Sociologist Howard Becker offers a compelling analysis of improvisation and everyday life in an interview conducted by Elizabeth Jackson (2010).

${ }^{2}$ For examples, see Adams (2010), Fischlin and Heble (2004), MacDonald (2011), Oliveros, and Ramshaw (2010).

\section{Works Cited}

Adams, W. A. "I made a promise to a lady': Critical Legal Pluralism as Improvised Law in Buffy the Vampire Slayer." Critical Studies in Improvisation 6.1 (2010). Web. 18 Feb. 2010.

Adler, Nancy J. "The Arts \& Leadership: Now that we can do anything, what will we do?" Academy of Management Learning and Education 5.4 (2006): 486-99. Web. 30 Jan. 2012.

Arrighi, Giovanni. The Long Twentieth Century: Money, Power, and the Origins of our Time. London: Verso, 1994. Print.

Arts for Art. "Mission." Web. 30 July 2012. <http://artsforart.org/about/mission>

Austin, Rob and Lee Devin. Artful Making: What Managers Need to Know about How Artists Work. Upper Saddler River, New Jersey: FT Prentice Hall, 2003. Print.

Bailey, Derek. Improvisation: Its Nature and Practice in Music. New York: Da Capo Press, 1993. Print.

Becker, Howard. Art Worlds. Berkeley: University of California Press, 1982. Print.

Benkler, Yochai. The Penguin and the Leviathan. New York: Crown Business, 2011. Print.

Boltanski, Luc and Eve Chiapello. "The New Spirit of Capitalism." International Journal of Politics, Culture, and Society 18 (2005): 161-88. Web. 7 July 2012.

Fischlin, Daniel and Ajay Heble, eds. The Other Side of Nowhere: Jazz, Improvisation, and Communities in Dialogue. Middletown: Wesleyan University Press, 2004. Print.

Heble, Ajay. "About ICASP." Improvisation, Community, and Social Practice. n.d. Web. 30 Jan. 2009. <http://www.improvcommunity.ca/about> 
Jackson, Elizabeth. "'A Second Standpoint': Howard Becker talks about music, sociology, and their intersections." Improvisation, Community, and Social Practice, 22 Nov. 2010. Web. 21 Feb. 2012. <http://www.improvcommunity.ca/research>

Jameson, Fredric. The Cultural Turn: Selected Writings on the Postmodern, 1983-1998. London: Verso, 1998. Print.

---. "Postmodernism, or the Cultural Logic of Late Capitalism." The New Left Review I.146 (1984): 53-92. Web. 7 July 2012.

Lears, T.J. Jackson. "The Concept of Cultural Hegemony: Problems and Possibilities." The American Historical Review 90.3 (1985): 567-93. Web. 7 July 2012.

Lewis, George E. "Teaching Improvised Music: An Ethnographic Memoir." Arcana: Musicians on Music. Ed. John Zorn. New York: Granary Books, 2000. 78-109. Print.

MacDonald, Chris. "Crisis Management as Ethical Improvisation." The Business Ethics Blog. Archive for December 2011. Web. 18 Feb. 2012. <http://businessethicsblog.com/2011/12/05/crisis-management-as-ethicalimprov/>

Noble, Steve. Personal interview. 16 Mar. 2007.

Oliveros, Pauline. “Adaptive use musical instruments.” Deep Listening Institute, n.d. Web. 18 Feb. 2012. <http://deeplistening.org/site/adaptiveuse $>$

Phillips, Barre. Personal interview. 25 June 2007.

Prévost, Edwin. Minute Particulars: Meanings in Music-Making in the Wake of Hierarchical Realignments and other Essays. Matching Tye, England: Copula, 2004. Print.

Ramshaw, Sara. “Jamming the Law: Improvised Theatre and the 'Spontaneity' of Judgment." Law Text Culture 14.1 (2010): 133-59. Web. 18 February 2012.

Sawyer, R. Keith and Stacy DeZutter. "Distributed Creativity: How Collective Creations Emerge from Collaboration." Psychology of Aesthetics, Creativity, and the Arts 3.2 (2009): 81-92. Web. 30 Jan. 2012.

---. "Education for Innovation.” Thinking Skills and Creativity 1.1 (2006): 41-8. Web. 30 Jan. 2012.

---. Group Genius: The Creative Power of Collaboration. New York: Basic Books, 2007. Print.

Small, Christopher. Musicking: The Meanings of Performing and Listening. Middletown: Wesleyan University Press, 1998. Print.

Smith, Greg. "Why I am leaving Goldman Sachs." The New York Times. Web. 18 Jul. 2012. <http://www.nytimes.com/2012/03/14/opinion/why-i-am-leaving-goldman-sachs.html?pagewanted=all>

Stanford, Jim. Economics for Everyone: A Short Guide to the Economics of Capitalism. Halifax and Winnipeg: Fernwood Publishing, 2008. Print.

Thomson, Scott. “The Pedagogical Imperative of Musical Improvisation." Critical Studies in Improvisation 3.2 (2007). Web. 30 Jan. 2012.

Wastell, Mark. Personal interview. 2 June 2007.

Whyte, David. Crossing the Unknown Sea: Work as a Pilgrimage of Identity. New York: Riverhead Books, 2001. Print. 